On the proposal of the finance committee the unit of subscription from the adhering countries was lowered. It was hoped that this might check any further secessions of countries on financial grounds, Australia and South Africa having resigned on that score. Two new countries-India and the Vatican State-were reported as adhering since the last General Assembly, while Roumania had become a fully subscribing member of the Union. As in the number of countries adhering, so also in the numbers of commissions there were changes. The commission on dynamical astronomy was abolished at its own request, while new commissions on 'Selected Areas' and spectrophotometry were formed. The solar commission broke up once more into its earlier constituent parts in the form of commissions on sunspots, chromospheric phenomena, solar spectroscopy and radiation and eclipses.

In addition to the technical discussions and the international organisation in the commissions there was an interesting visit to the Harvard College Observatory and to its new station at Oak Ridge for a 61-inch reflector; later a demonstration was given of eclipse results so far as they could be announced. Good results may be expected apparently from chromospheric spectra obtained by the falling plate method by the Lick observers, and a very nice flash was secured by the Greenwich observers- the only British expedition in Canada which had any luck at all. Nice pictures of the corona were secured by a number of expeditions, notably the Lick party which also at last obtained some interference fringes from the coronal line. Good polarisation results are hoped for from the French and the Harvard expeditions. Amongst other interesting slides shown at the meeting were the coronal spectrograms and photographs secured by M. Lyot, of the Paris-Meudon Observatory, without the aid of an eclipse.

The next meeting of the General Assembly was fixed for 1935 (probably early July) in Paris on the invitation of the French astronomers. The newly elected executive committee to serve until then consists of Prof. F. Schlesinger (United States), President; Prof. T. Banachiewicz (Poland), Prof. E. Bianchi (Italy), Prof. C. Fabry (France), Prof. N. E. Norlund (Denmark), Prof. F. Nus̃l (Czechoslovakia), Vice-Presidents ; Prof. F. J. M. Stratton (Great Britain), General Secretary.

\title{
Recent Researches on Cosmic Rays
}

IN the Times of October 8, Prof. A. Piccard gives 1 an account of his experiments on the cosmic rays during his balloon ascent on August 10, in which he was accompanied by Max Cosyns, and reached a maximum height of 53,672 feet. Two distinet types of observations on the cosmic rays were made on this occasion, one to determine the variation of intensity of the rays with height, and the other to determine the distribution of the radiation in different directions.

The observations on the change of intensity were apparently made in the usual way by measuring the ionisation produced in a sealed vessel. Prof. Piccard states that his results over the same range of height are in good agreement with those found by Prof. Regener, of which an account was given in a letter published in NATURE of September 3. It will be recalled that in Regener's experiments, self-registering apparatus was attached to a free balloon which reached a much greater height than Piccard's balloon. He found that the intensity of the radiation increased rapidly at first with altitude, then more slowly, and finally reached what appeared to be a constant maximum at the greatest heights. The free balloon of Regener rose to a point where the barometric pressure was about $25 \mathrm{~mm}$., while the lowest pressure reached by Piccard was $73 \mathrm{~mm}$. The concordant results obtained by the two observers thus give us new and valuable information of the apparent variation of intensity of the rays up to the highest altitudes that are likely to be reached for some time to come.

The second type of experiment made by Piccard was to determine the direction of the cosmic rays by using a tubular Geiger counter. This device has the property of distinguishing to some extent between rays coming from different directions. At the earth's surface it can be shown with this apparatus that the rays come predominantly downwards. In striking contrast to this, Piccard finds no such directional effect at high altitudes, and thus concludes that the radiation at such great heights is uniform in all directions. He provisionally suggests that the cosmic rays have their origin in the stratosphere. $\mathrm{He}$ is, however, careful to point out that this is not the only possible explanation. For example, little if any directional effect would be expected if the rays were actually cosmic in origin and fell on the earth uniformly in all directions. Whatever may be the ultimate interpretation of these observations, they constitute an important contribution to our knowledge.

A vigorous attack on the problem of the nature of the cosmic rays is now being made by several new and powerful methods. The experiments of Regener and Piccard afford trustworthy information of the variation of intensity of the rays with altitude, while the work of many experimenters has given us accurate data of the absorption of the radiation for great depths of water and for other absorbing material. The earlier observations of Millikan had indicated that the intensity varied little if at all on the earth's surface. This important question has been again examined by Prof. A. H. Compton during the past year in the course of his travels in the northern and southern hemispheres. $\mathrm{He}$ made observations of the relative intensity of the cosmic rays by the ordinary ionisation method. $\mathrm{He}$ concludes that there is a marked change of intensity at different parts of the earth, especially

No. 3285, VoL. 130] 
for the softer components of the radiation. In a recent communication to the Physical Review (Sept. 1, 1932) he concludes that there is a definite correlation between the intensity of the cosmic rays and the direction and magnitude of the earth's magnetic field. The intensity in general is higher the greater the angle of magnetic dip. The dependence of the intensity of the cosmic rays on magnetic latitude has also been convincingly shown by Clay and Berlage from continuous observations on a voyage from Amsterdam to Batavia.

Such a relation between intensity of the rays and the earth's magnetic field is to be expected on general grounds if the radiation consists of a stream of swift charged particles. It will be remembered that Prof. C. T. R. Wilson long ago suggested that the cosmic radiation may originate from thunderstorms in our atmosphere. In the intense electrical fields that precede a lightning flash, it is probable that electrons and other charged particles may acquire a very high velocity. If some of these pass out into space, their paths will be bent by the earth's magnetic field and a few may eventually re-enter our atmosphere. In the light of the new observations, such a possible origin of the cosmic radiations should not be overlooked. In this connexion, it should be noted that Schonland in South Africa has found that the intensity of the rays is suddenly altered by the occurrence of distant lightning flashes, but no such effect is observed immediately beneath the thundercloud.

The question of the nature of the cosmic rays is still a matter of much discussion--whether, for example, the primary radiation is of the $\gamma$-ray type or consists of a stream of fast electrons or protons-but there seems to be a growing belief that the main part of the radiation is corpuscular in character. This question is now being actively investigated by photographing the tracks of the ionising particles in an expansion chamber and observing the curvature of these tracks due to a strong magnetic field. By this method Millikan and Anderson have found that not only are swift electrons present, but also positively charged particles believed to be swift protons. Many of these particles undoubtedly have energies corresponding to several hundred million electron volts. Blackett and Occhialini (NATURE, Sept. 3, 1932) have made experiments of a similar kind using an ingenious device whereby the passage of an ionising particle through two Geiger counters in line is made to actuate an expansion chamber, placed between the counters, within a hundredth of a second of the passage of the radiation. By this device the accumulation of data should be much more rapid. By the full use of these powerful methods, we may hope soon to obtain definite information as to the nature and energy of these ionising particles, and of the effects produced by them in their passage through matter.

Reference should also be made to another strange type of occurrence observed with the cosmic rays. Hoffmann and Steinke and Schindler have observed sudden bursts of ionisation in a measuring vessel, of a magnitude far exceeding that produced by the swiftest $\alpha$-particle known. It has been suggested that these bursts of ionisation arise from some type of disintegration process brought about by the cosmic rays: whatever may be the explanation, there can be no doubt these observations suggest a fascinating if difficult field for further research. It should be mentioned that Compton, in his recent experiments already referred to, noted that these bursts of ionisation are much more frequent at high altitudes, and suggested that they may be due mainly to an effect of the softer components of the radiation.

The problem of the origin and the nature and properties of the cosmic rays is one of the most interesting in the domain of physics. It is to be hoped that the concentrated attack from so many different directions will soon bring more definiteness to our knowledge of this obscure type of radiation.

\section{Obituary}

Mr. Winliam G. Collingwood

$\mathrm{T}$ $\mathrm{HE}$ death of William Gershom Collingwood, artist, archæologist and author, at the age of seventy-eight years, took place at Coniston on Oct. 1. The son of a well-known landscape painter, W. Collingwood, he was born at Liverpool on Aug. 6, 1854, and matriculated at University College, Oxford, in 1872. While at Oxford, where he took first class honours in Literae Humaniores, he formed a close friendship with Ruskin, then Slade professor, and when the health of the latter broke down, accompanied him abroad to France and Italy, later settling near him at Windermere. Here he occupied himself in landscape painting, editing Ruskin's works and lecturing on the theory and history of art. After Ruskin's death he was for some time professor of art at the University of Reading.
In Cumberland Collingwood had come into contact with members of the Cumberland and Westmoreland Antiquarian Society and had been attracted to the study of Icelandic literature and the archæology of the Norse settlements in the north of England. The first fruits of his studies, however, took the form of fiction, his first novel appearing after a visit to Iceland in 1897. Illdirected criticism of his second venture "The Bondwoman", notwithstanding its high literary merit, diverted him to a more intensive study of the Norse and Anglian archæology of northern England, especially on its artistic side, upon which he became widely recognised as the first authority. A long series of papers in the Proceedings of the Antiquarian Society, of which he became editor, culminated in the publication of an exhaustive and

No. 3285, Vol. 130] 